OPEN ACCESS

Edited by:

Murat Akova,

Hacettepe University, Turkey

Reviewed by:

Jurica Arapović,

University Clinical Hospital Mostar

Bosnia and Herzegovina

Teclegiorgis Gebremariam, Lundquist Institute for Biomedical Innovation, United States

${ }^{*}$ Correspondence: Dong Ming Li dorisli@126.com dongmingli@bjmu.edu.cn

Specialty section: This article was submitted to Infectious Diseases - Surveillance,

Prevention and Treatment, a section of the journal

Frontiers in Medicine

Received: 30 July 2020 Accepted: 25 March 2021

Published: 02 June 2021

Citation:

Li DM, Lun LD, Ge J, Zhang GJ, Li XL and de Hoog GS (2021) Case Report:

Rhizopus arrhizus

Rhino-Orbital-Cerebral Mycosis and Lethal Midline Granuloma: Another

Fungal Etiological Agent

Front. Med. 8:578684.

doi: 10.3389/fmed.2021.578684

\section{Case Report: Rhizopus arrhizus Rhino-Orbital-Cerebral Mycosis and Lethal Midline Granuloma: Another Fungal Etiological Agent}

\author{
Dong Ming Li ${ }^{1 *}$, Li De Lun ${ }^{2}$, Jie Ge ${ }^{1}$, Gong Jie Zhang ${ }^{1}$, Xin Lun $L i^{2}$ and G. Sybren de Hoog ${ }^{3}$ \\ ${ }^{1}$ Division of Dermatology \& Mycological Lab, Peking University Third Hospital, Beijing, China, ${ }^{2}$ Division of Nephrology, Air \\ Force General Hospital, Beijing, China, ${ }^{3}$ Center of Expertise in Mycology of Radboud University Medical Center, Canisius \\ Wilhelmina Hospital, Nijmegen, Netherlands
}

Objective: Both rhino-orbital-cerebral mycosis and lethal midline granuloma (LMG) may result in midline destruction. LMG has now been generally considered as a natural killer/T cell lymphoma, nasal type (ENKTL-NT) with an association of EBV. Fungi have been detected from the diseased tissues now and then but are often considered as lymphoma-associated infections. We previously reported an ENKTL-NT case with Mucor irregularis, which played a causal role in the disease and was involved in the overexpression of Ki67 and CD56 in the mouse experiment. The present study describes a chronic Rhizopus arrhizus infection with immunological parameters that are closely similar to LMG. We aim to explore the relationship of another Mucorales fungus, $R$. arrhizus, and LMG in a patient and in mice.

Methods: Case study and mouse infection modules were designed for our observation. A 35-year-old man with midline face ulcers which was clinically suspected as LMG was selected. Biopsy specimens were sent for lymphoma diagnosis and microbiological detection. The isolated fungus was tested in an ICR mouse model for mycological and histological analyses.

Results: Five tissue samples yielded Rhizopus arrhizus. In the pathology, characteristic inflammation, necrosis, and granulation with thin-walled hyphae are observed. Immunohistochemistry showed NK/T cell infiltration (CD3+, CD8+, TIA1+, GZMB+, PRF+, individual CD56+) with hyperplasia $(\mathrm{Ki67+)}$ and angioinvasion. The patient recovered completely with amphotericin $\mathrm{B}$. In the murine experiment, $R$. arrhizus caused angioinvasion with $\mathrm{NK} / \mathrm{T}$ cell infiltration (CD3+, $\mathrm{CD} 56+, \mathrm{TIA} 1+, \mathrm{GZMB}+, \mathrm{PRF}+)$ with proliferation $(\mathrm{Ki67+})$ and was re-isolated from the infected host.

Conclusions: We here describe a mid-face destruction patient, which was diagnosed by the top pathologists in China according to the current criteria of NK/T cell lymphoma, with a negative result for EBV and positive result for $R$. arrhizus. With a then developed mouse experiment, the $R$. arrhizus in the diseased lesions was responsible for the NK/T cell infiltration (CD3+, CD8+, CD56+, TIA1+, GZMB+, PRF+), proliferation (Ki67+), 
and angioinvasion, suggesting another fungal etiological agent for LMG, which could be eradicated with amphotericin B.

Limitations: The sample size is not sufficient for statistical analysis. However, our findings are suggestive for the role fungus plays in LMG.

Keywords: midline face destruction, Rhizopus arrhizus, rhino-orbital-cerebral mycosis, NK/T cells, Rhizopus oryzae, lethal midline granuloma

\section{INTRODUCTION}

Lethal midline granuloma (LMG) is a clinical-pathological entity characterized by progressive midline face ulceration, granulation, and destruction, with a high mortality rate $(1,2)$. The disorder was first described as a malignant granuloma for the rapid destruction of the face and nose by Mcbride in $1897(3,4)$. With a variety of descriptive names such as "nonhealing granuloma," "granuloma gangraenescens," "malignant granuloma," "idiopathic midline destructive disease," and "lethal midline granuloma" (5-8), it is now known as the "extra nodule natural killer NK/T cell lymphoma, nasal type (ENKTL-NT)," because natural killer cells,although on a lesser extent $\mathrm{T}$ cells, are often detected along with cytotoxic granule associated proteins (9-11). However, diagnosis and treatment of LMG has remained challenging; in some cases, the condition of patients worsened due to anti-cancer therapy $(2,12-16)$ in the early or later stages (17), or achieved resolution with antifungal therapy alone or in combination with other medication (18-21), as what can also be obtained with rhino-orbital-cerebral mucormycosis (ROCM) (22).

The role of fungi isolated from clinical sites may be unclear. However, the clinical similarity of mucoralean fungal infections may lead to an inappropriate therapy. Mixed cases have been reported where the fungal infection was cured but the anticancer therapy was continued, leading to adverse results $(2,23)$. Some LMG patients received chemotherapy, but post-mortem, the cause of their disorder was shown to be fungal $(24,25)$. In patients primarily diagnosed with ROCM, the detection of NK cells and/or T cells in the tissue led to a change of diagnosis to from ROCM to LMG, with a fatal outcome $(1,26)$. In another paper, two ROCM cases were reported with NK/T cells and angiocentric characteristics. Diagnosis for one patient was changed from ENKTL-NT to ROCM as fungal mycelium was seen in the tissue, while the diagnosis for the other was from ROCM to NK/T cell lymphoma because the NK/T cells were seen in the tissue (27). These cases suggest the ambiguity in understanding the role of fungi in the development of midline ulcers $(27,28)$.

We previously identified a chronic infection by Mucor irregularis as the fungal cause of a case resembling LMG $(28,29)$. Since other mucoralean fungi tend to cause acute infections in susceptible patient populations, it seemed unlikely that other Mucorales fungi could be associated with the disorder. Here, we report a case of a Chinese male who presented with midline facial destruction which was diagnosed as LMG, but the etiologic agent was Rhizopus arrhizus, another member of Mucorales, confirmed in histopathology and isolation. Replication of NK/T cells, angioinvasion, and hyperplasia were observed and reproduced in a mouse model.

\section{Case Presentation}

A 35-year-old Chinese male with diabetes mellitus presented to Peking University Third Hospital (Beijing, China) on November 14, 2011, with progressive swelling, ulceration, and destruction of the face. The lesions had begun 2 months earlier as infiltrated rhino facial and maxillofacial erythema, with nasal obstruction, discharge, rhinorrhea, and epistaxis, which rapidly increased in size and ulcerated. The patient was initially diagnosed, in the local hospital, with periodontitis and the treatment with tooth extraction was ineffective. Next, the lesion was diagnosed with skin and subcutaneous infection in the rhino face and treatment with antibiotics was administered, but the necrotic ulcer progressively enlarged. Subsequent clinical diagnosis was made of rhino facial mycosis and the patient was treated with itraconazole, but the ulcer still progressed with the disease eroding through his hard palate, sinuses, nose, and face, resulting in destructive changes in the maxilla and mandible, with systemic manifestations of fever, weight loss, and hepatosplenomegaly. As the ulceration progressed, he was suspected as having LMG and was therefore transferred 2 weeks after to the university clinic for further diagnosis and treatment.

On examination, his left half central face was swollen, ulcerated, and destructed, and the nose, lower eyelid, chin, and upper lip were all necrotic. Black eschar covered the left side of the face with an underlying grayish pus (Figure 1A). The anterior wall of the left maxilla was perforated with a greenyellowish pus seen at the bottom of the maxilla (Figure 1B). The hard palate had patches of black, pale discoloration showed perforation (Figure 1C), and soon proceeded with complete destruction (Figure 1D). Pale gray, wool-like mycelium was observed on the necrotic tissue of the nose (Figure 1E). The patient had a normal temperature, pulse, respiration, and blood pressure. His body weight was $42 \mathrm{~kg}$ ( $20 \mathrm{~kg}$ less than before onset). Blood tests showed levels of hemoglobin: $90 \mathrm{~g} / \mathrm{L}$, white cells: $7.5 \times 10^{9} / \mathrm{L}$ with $81.8 \%$ band cells, platelets: $433 \times 10^{9}$ /L, blood glucose level: $17.7 \mathrm{mmol} / \mathrm{L}$, total iron binding capacity: $40.2 \mathrm{~mol} / \mathrm{L}$, transferrin: $147 \mathrm{mg} / \mathrm{dL}$, prothrombin time: $14.2 \mathrm{~s}$, prothrombin activity: 61.0 (80-150), alanine aminotransferase: $43 \mathrm{U} / \mathrm{L}$, alkaline phosphatase: $394 \mathrm{U} / \mathrm{L}$, and r-GT: $354 \mathrm{U} / \mathrm{L}$. The tests for HIV Ab, anti-TB, EBV IgM, and syphilis were all negative. X-ray computed tomography (CT) showed left facial soft tissue deficiency, absence of left anterior bone wall 

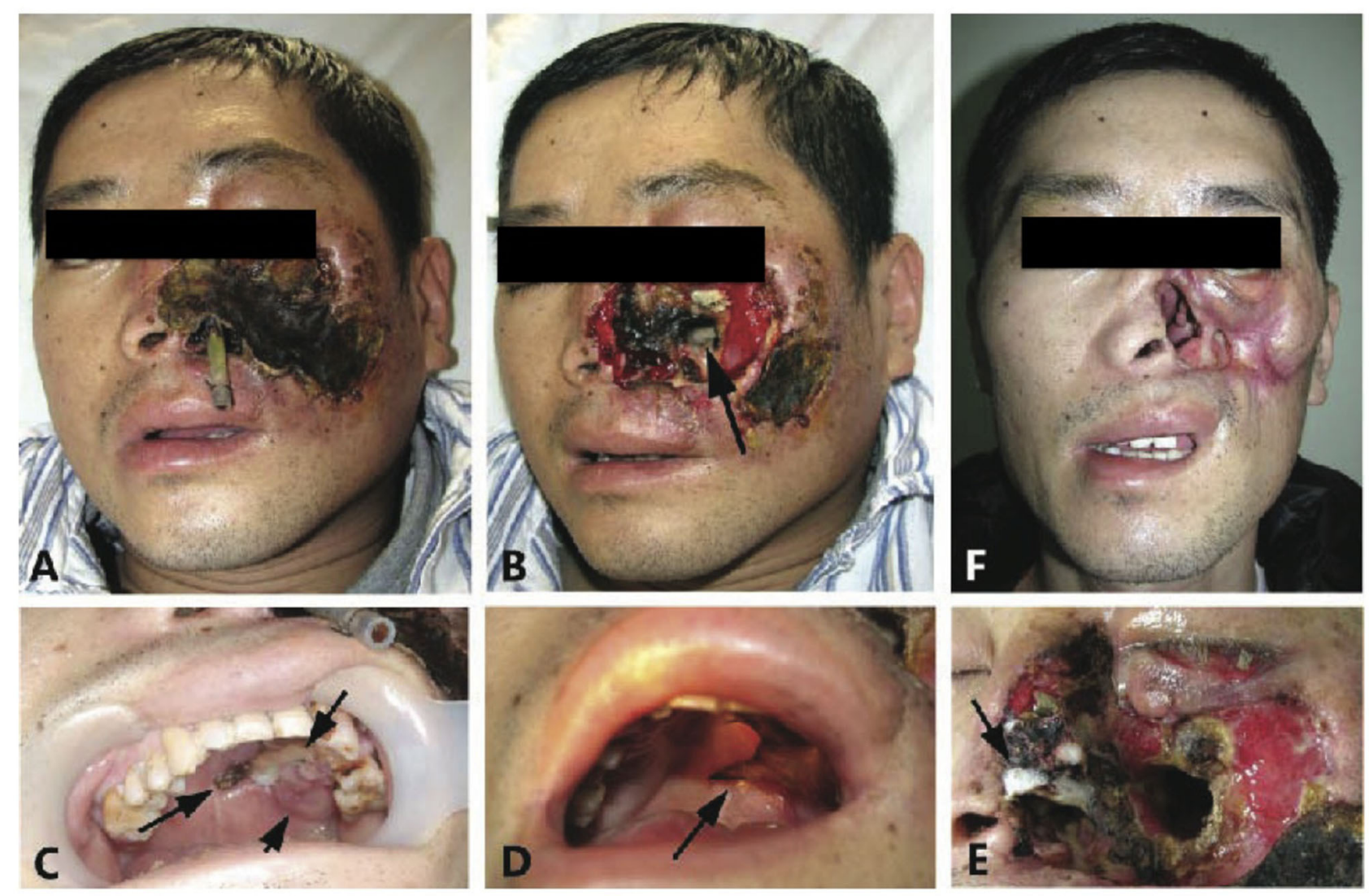

FIGURE 1 | "Rhizopus arrhizus associated lethal midline granuloma/rhino-orbital cerebral mycosis." Destruction of the sinus, nose, face, palate, and orbit; defects of the left sided external nose, soft tissues, and the front wall of the maxillary sinus; and yellow pus was seen within the left maxillary sinus. (A,B) Show patient onset before and after debridement with biopsies. (C) Reveals the patches dark discoloration (short arrow), light discoloration (medium arrow), and perforation (long arrow) of the hard palate that represent inflammation, ischemia, and necrosis, respectively. (D) Shows widespread destruction in the left side of the palate (arrow). (E) Reveals pale gray wool-like mycelium grown on the necrotic nose tissue (arrow). (F) Shows complete remission with scars 4 months after antifungal therapy.

of the maxillary sinus, mucosal thickening with increased density of bilateral maxillary sinus, ethmoid, sphenoid sinus, bilateral hydrothorax, and high-density fuzzy shadow in the lower part of the lungs. Meningeal enhancement was seen on MRI.

A skin biopsy was performed on the lesions of the nasal dorsum, nasal mucosa, and granuloma. The biopsied tissue was sent for lymphoma diagnosis to the authored pathologists for microbiological evaluation in our laboratory. Pathology showed inflammation, necrosis, and pleomorphic cell infiltration, with atypical hyperplasia. Angioinvasive, angiocentric, and angiodestructive characteristics were typical with "Onionskin" lesions (Figure 2A). In immunohistochemistry, the atypical lymphoid cells were positive for NK/T cell markers $(\mathrm{CD} 2+, \mathrm{CD} 3+, \mathrm{CD} 8+$, and individual CD56+), cytotoxic granule associated proteins (GZMB and TIA1), and hyperplasia (Ki67+) - typical of ENKTL (Figure 2). Patient was diagnosed as LMG/T cell non-Hodgkin's lymphoma at the Department of Pathology, Peking University, according to the WHO classification of mature T- and NK-cell neoplasms with negative EBER and EBV testing $(9,10)$.

\section{Multi-Stage Diagnostics}

Five biopsy specimens were taken from different tissues on the nasal mucosa, edges of the ulcers, and eschar were cultured and were positive for a fungus that was later identified as Rhizopus by morphology (Figure $2 \mathrm{~B})$, and as $R$. arrhizus (=R. oryzae) by rDNA sequencing (D1/D2 and ITS1-ITS2 regions). The isolates were sensitive to amphotericin $\mathrm{B}(\mathrm{AMB})$ and resistant to fluconazole, itraconazole, and voriconazole. Microscopy of pathological slides, which did not detect EBV RNA EBER1 with in situ hybridization, revealed large amounts of broad, aseptate, thin-walled hyphae in the affected tissue, artery walls and lumens. Thrombosis was observed that was surrounded with ischemic necrosis. In addition, angiodestructive characteristics were seen along small arteries which were filled with hyphae. "Onion-skin" lesions with fungal elements were seen upon the cross section of the involved arteries (Figures 2C,D). Comparing multiple biopsy specimens sampled from the edge of the newly infected tissues with those in necrotic tissues, we found that typical hyphae could be observed in the newly affected tissues only, whereas atypical dysplasia were seen with positive $T$ cell markers (a few spots with $\mathrm{NK} / \mathrm{T}$ cell makers) in the granulomatous tissue, with thin-walled 


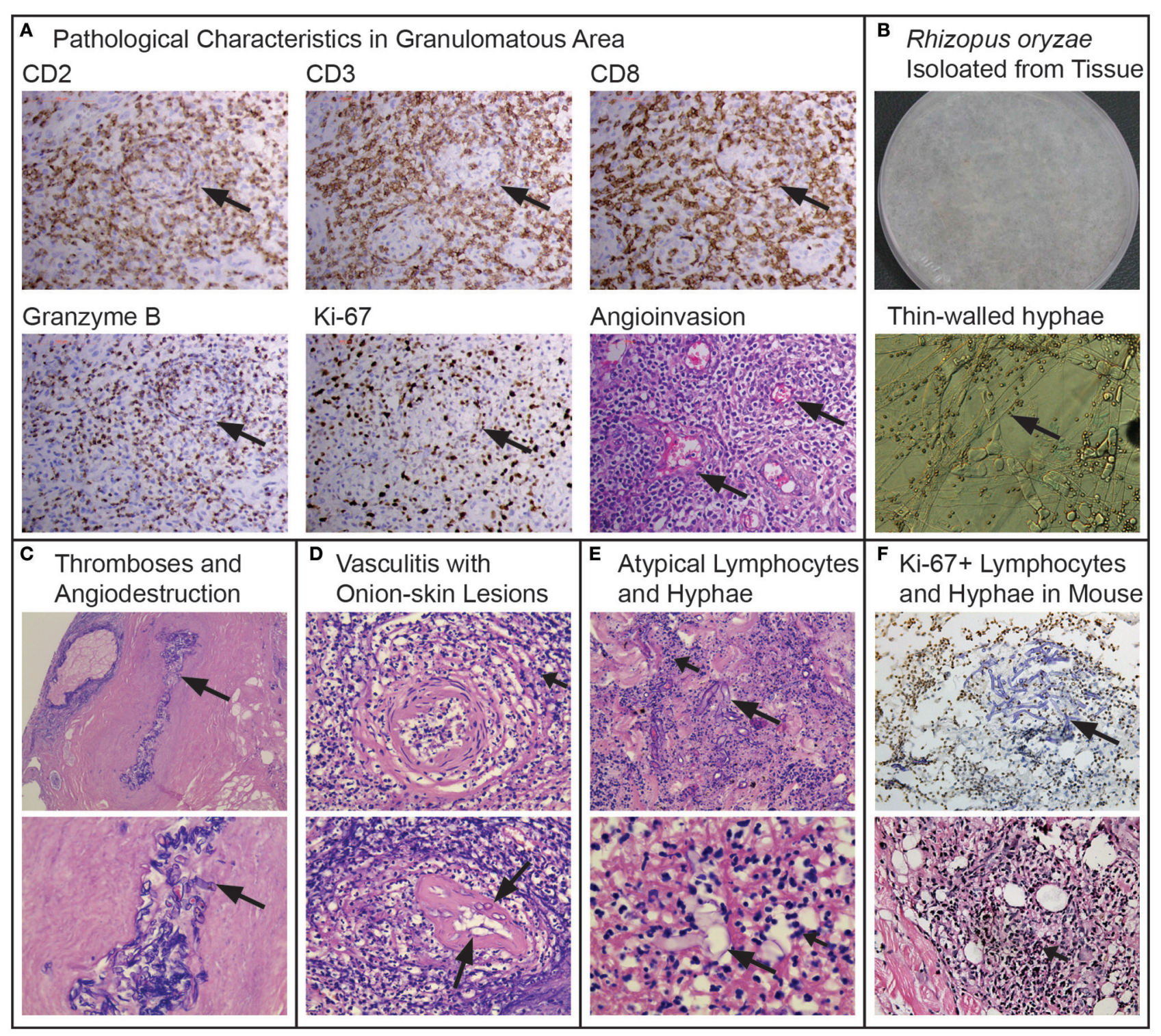

FIGURE 2 | "Rhizopus arrhizus associated lethal midline granuloma/rhino-orbital cerebral mycosis." Pathologic characteristics of the midline face destruction patient, the fungus and hyperplasia replicated in the mouse models. (A) Shows the pathological characteristics in the granulomatous area with immunohistochemically positive staining of CD2, CD3, CD8, GranzymeB, and Ki-67 from granulomatous tissues (Envision method, original magnification $\times 400)$ and angioinvasion ( $\mathrm{H} \& \mathrm{E}$, original magnification $\times 400$ ). (B) Rhizopus arrhizus (PUTH 20111112) isolated from tissue: lanose appearance with grayish color 5 days growth on PDA and thin-walled hyphae (arrows) and conidia (lactophenol cotton blue staining, original magnification $\times 400)$. (C) Fungal thromboses (long arrow), angiodestruction and angiocentric coagulative necrosis (short arrows, H\&E, original magnification $\times 200$ and $\times 400$, respectively). (D) Atypical cells (short arrows) and hyphae (long arrows) among Onion-skin lesions (H\&E staining, original magnification $\times 400)$. (E) Atypical lymphoid cells (short arrows) and hyphae (long arrows) (H\&E staining, original magnification $\times 400$ and $\times 1,000$, respectively). (F) Ki-67 positive cells and hyphae with immunochemical staining in mouse infected by Rhizopus arrhizus (PUTH 20111112) (Envision method, original magnification $\times 400$ ) hyperplasia with H\&E staining (original magnification $\times 400$ )

hyphal elements and spores that were broken or endocytosed by the nucleate or giant cells, some of which were atypical with a high index of Ki67 expression (Figure 2).

We re-diagnosed the patient as having LMG associated with $R$. arrhizus infection (ROCM/LMG) and initiated treatment with intravenous AMB (25 mg once daily) accordingly, and gradual improvement was observed as the ulcers became smaller. Thirty-four days after the onset of therapy, he was transferred to the Plastic Surgery Department for skin transplantation. AMB treatment was discontinued and a relapse was noted 12 days after. He returned to the local hospital and restarted AMB treatment. Because of the serious side effects of hypopotassemia and tachycardia, he was transferred to the Division of Nephrology in the General Air Force Hospital 1 
week after the recurrence, where he was treated with liposomal AMB (L-AMB) at a dosage of $50 \mathrm{mg}$ daily for 2 months. With a total dosage of $1,055 \mathrm{mg}$ of $\mathrm{AMB}$ and $2,600 \mathrm{mg}$ of $\mathrm{L}$ $\mathrm{AMB}$, the destructed area was completely healed with scars (Figure 1F). Ten months later, he was successfully transplanted with a thick skin graft from his thigh for the reconstruction of the nose and chin. At follow-up, he lives a normal life up to now.

\section{METHODS}

\section{Specimen Collection and Mycology}

Five biopsy specimens taken from different tissues of the nasal mucosa, edges of ulcers, and eschar were cultured on Sabouraud's glucose agar (SGA) and yielded the same fungus recorded as PUTH 20111112. The organism recovered from the primary culture was grown on potato dextrose agar (PDA) at $28^{\circ} \mathrm{C}$ for 4 days. Genomic DNA of the isolate was extracted by using the Biospin Fungus Genomic DNA sequence of the internal transcribed spacer region (ITS) and the D1-D2 regions of the large subunit ribosomal DNA were amplified by using primer pairs ITS4/ITS5 (5'-GGTCCGTGTTTCAAGACGG-3'/5' -GGA AGTAAAAGTCGTAACAAGG-3') and D1/D2 (5' - AGCGG AGGAAAAGAAACTA-3' $/ 5^{\prime}$ - ACGATCGATTTGCACGTCAG$\left.3^{\prime}\right)$, respectively. The amplification products were then sequenced by BGI (Beijing, China). The obtained sequences were compared with those in the GenBank (https://blast.ncbi.nlm.nih.gov/).

\section{Animal Experiments Isolates and Mice}

Subcultures of PUTH 20111112 were grown on SGA at $28^{\circ} \mathrm{C}$ for 4 days. Conidia were harvested by gently washing the surface of the slants with saline. The suspension was filtered through a sterile $40 \mu \mathrm{m}$ cell strainer and the number of conidia was adjusted to $5 \times 10^{7}$ colony-forming units per milliliter $(\mathrm{CFU} / \mathrm{ml})$ by counting the spores in a hemocytometer and subsequently verifying these results through quantitative colony counts on PDA plates. Resting conidia were immediately used or stored at $+4^{\circ} \mathrm{C}$.

Twenty ICR mice (male, 18-22 g, 6-8 weeks) were purchased from the SPF Animals Experimental Animal and Technology Co., Ltd. (Beijing) and bred in the animal experiment department of the 304 Hospital of PLA (Beijing) under specific-pathogen-free (SPF) conditions. Mice between 6 and 8 weeks of age were divided into two groups randomly, with 10 mice in each group. Group 1 was inoculated with spore suspension (5 McFarland standards) of $R$. arrhizus PUTH 20111112 on the back of the skin and group 2 with normal saline as the negative control.

\section{Establishment of Skin Infection Models}

Mice between 6 and 8 weeks of age were infected by an intracutaneous injection at the skin of the back with a suspension of $R$. arrhizus. Mice of group 1 were inoculated with $R$. arrhizus and mice of group 2 were intracutaneously injected with normal saline as control.

\section{Access and Process of Skin Specimens}

Every week after inoculation until week 5, skin specimens around the inoculation position from two mice in each group were collected to perform fungal culture in SDA and were embedded in paraffin and serially sectioned for the histopathological examination of Hematoxylin-eosin staining (H\&E), Periodic acid-Schiff staining (PAS), Periodic SchiffMethenamine staining (PASM), Calcofluor staining, and immunohistochemical staining.

\section{Antibodies}

The primary antibodies used for immunohistochemical staining targeting were CD56/NCAM (Neural Cell Adhesion Molecule), anti-CD3, PRF, GZMB, TIA1, and Ki-67 (all from Abcam, Boston, USA). The anti-rabbit antibody (Zhongshan Gold Bridge, Beijing, China) was used as the secondary antibody for the immunohistochemical staining. Unstained cells were used as negative controls and ovarian cancer slices were used as positive controls.

\section{Immunohistochemical (IHC) Staining}

Paraffin sections were dried at $60^{\circ} \mathrm{C}$ for $4 \mathrm{~h}$, and the paraffin was removed successively by immersing them into dimethylbenzene substitutes $(3 \times 15 \mathrm{~min})$, absolute ethanol $(2 \times 5 \mathrm{~min}), 95 \%$ ethanol $(2 \times 5 \mathrm{~min}), 80 \%$ ethanol $(5 \mathrm{~min})$, and distilled water ( $2 \mathrm{~min}$ ). The samples were incubated with $3 \%$ peroxide-methanol in a light resistant container at room temperature for $10 \mathrm{~min}$ for endogenous peroxidase ablation. All following steps were carried out in a moist chamber. The samples were rinsed three times with clean water, three times with distilled water, and three times in PBS (phosphate buffer solution, pH 7.4). CD3, CD56, GZMB, TIA1, PRF, and Ki67 antigens were retrieved by a high pressure and high temperature antigen retrieval method using a pressure cooker and immersed in citric acid buffer ( $\mathrm{pH}$ 6.0). The slides were then rinsed in PBS for $3 \times 5 \mathrm{~min}$. The anti-CD3, antiCD56/NCAM, anti-granzyme B, anti-TIA, anti-PRF, and anti-Ki67antibodies were diluted into 1:400-1:4,000 solutions separately and were dropped $50-100 \mu \mathrm{L}$ onto the slides at $4^{\circ} \mathrm{C}$ overnight. Then, 50-100 $\mu \mathrm{L}$ secondary antibody liquid was dropped onto the slides and incubated for $30 \mathrm{~min}$ at room temperature. The slides were rinsed in PBS for another $3 \times 5 \mathrm{~min}$. All slides were colorized with 3,3-diaminobenzidin (DAB, Zhongshan Gold Bridge, Beijing, China) $40 \mathrm{~s}$ for Ki-67 coloration and $80 \mathrm{~s}$ for CD3, CD56, GZMB, TIA1, PRF, and CD56 coloration. The cell nuclei were counterstained with hematoxylin, and then the slides were dehydrated and integrated with neutral balsam.

\section{RESULTS}

\section{Mycology}

Five biopsy specimens grew highly similar, grayish, filamentous colonies that were identified as Rhizopus arrhizus (R. oryzae) recorded as PUTH 20111112 (Peking University Third Hospital). With sequence analysis, the identification of $R$. arrhizus was confirmed with a high identity $(\geq 99 \%)$, high query coverage $(\geq 99 \%)$, and low E value $\left(\leq 10^{-5}\right)$. 


\section{A LMG markers}
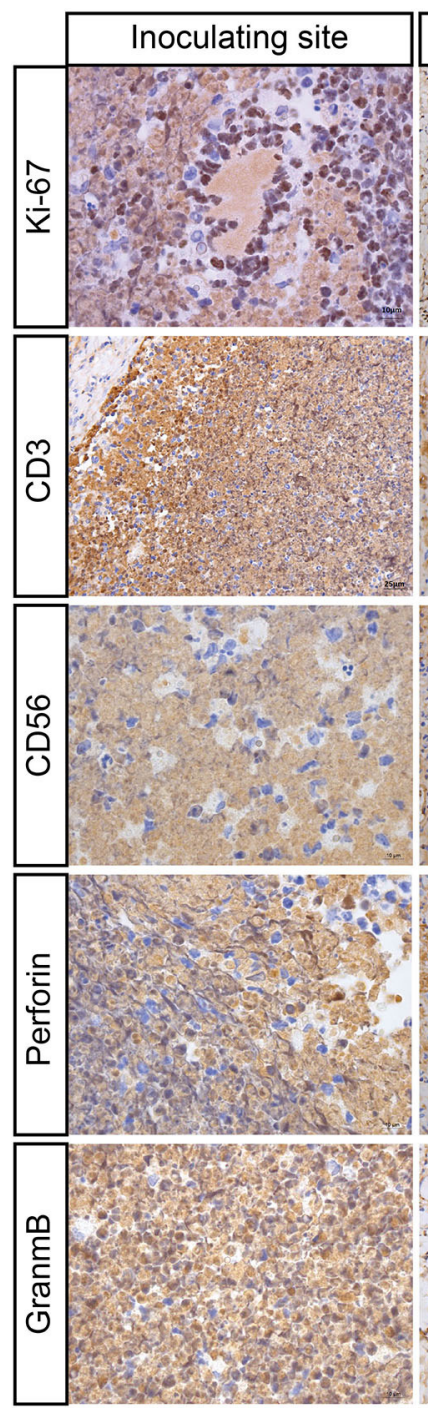
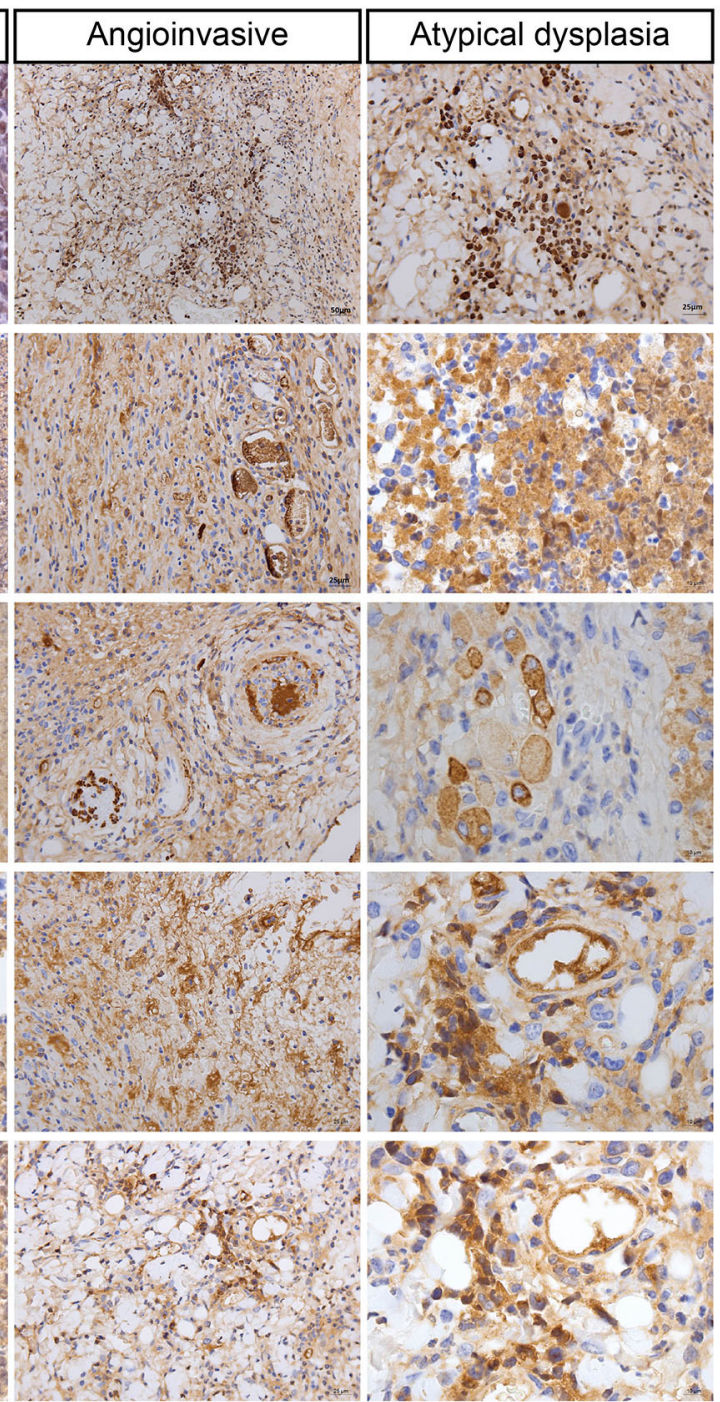

B Fungal elements
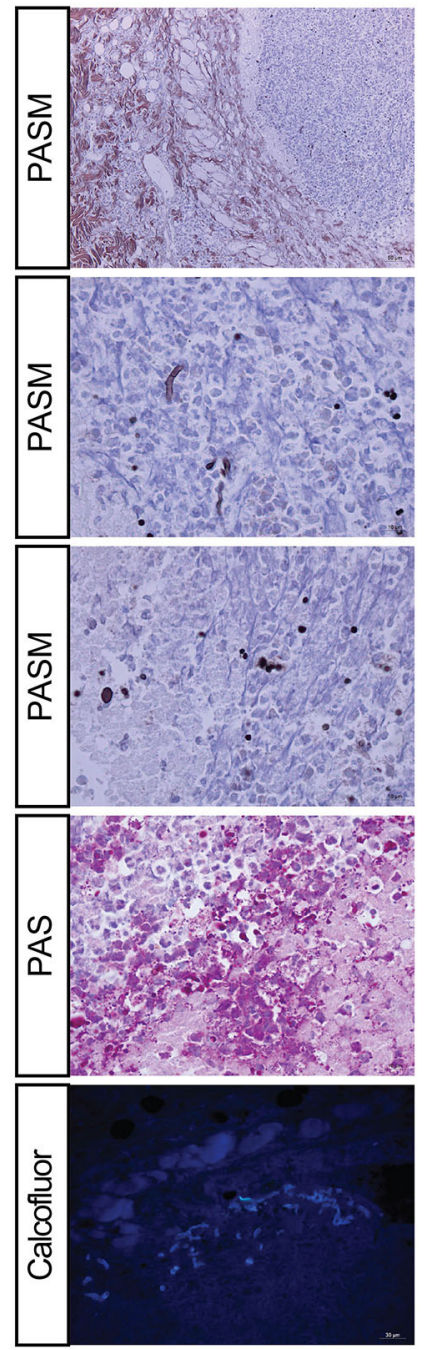

FIGURE 3 | "Mouse infection modules with Rhizopus arrhizus isolated in LMG patient. (A) Shows atypical dysplasia with immunohistochemically positive staining of Ki-67, CD-3, CD-56, PRF, and GZMB. (B) Shows hyphae (broken and disintegrated) and spores (endocytosed) by periodic acid-silver metheramine (PASM), Periodic Acid-Schiff stain (PAS), and Calcofluor staining".

\section{Animal Experiments \\ Skin Lesions Fungal Culture}

One week after inoculation, the mouse skin tissues of group 1 (with fungus) were inflamed and swollen with subsequent ulcers, while the control mice (group 2) were noted as inflamed. Tissue re-cultivations for fungus were positive in group 1 and negative in group 2 .

\section{Pathological and Immunohistochemical Manifestations}

Nodules and ulcers were induced by R. arrhizus PUTH 20111112. Under the microscope, angioinvasion, necrosis, granulation, and inflammation have been observed with pleomorphic cells. In some areas, atypical cells were seen with irregular nuclear margins and nuclear hyperchromasia. These cells were also positive for Ki-67, CD3, CD56, TIA1, GZMB, and PRF. Thinwalled hyphae and spores could be seen in the inoculated sites. The Ki-67 positive cells were mostly accumulated around hyphae (Figures 2F, 3). With an increased distance to the inoculation site, the mycelium became atypical and more difficult to identify. Thin-walled hyphae appeared in different forms and could be distorted, broken, disintegrated, or endocytosed that were hardly observed even with PAS and PASM staining (Figure 3).

\section{DISCUSSIONS}

Our patient was characterized by: (a) nasal airway obstruction with rhinorrhea and epistaxis; $(b)$ progressive nose, palate, and 
middle face swelling, ulceration, and destruction with signs of orbital and cerebral involvement; (c) inflammation with pleomorphic cell infiltrations; $(d)$ expression of NK-cell or T cell markers [CD2+, $\mathrm{CD} 3+, \mathrm{CD} 56-$ (individual CD56+), CD8+], more than one cytotoxic granule associated proteins (GZMB, PRF, and T-cell restricted intracellular antigen); (e) vascular damage with angioinvasive, angiocentric, and angiodestructive lesions, and "Onion-skin" feature; $(f)$ atypical dysplasia. The case was first diagnosed as LMG (T cell non-Hodgkin's lymphoma) $(9,10)$ and was expected to undergo chemotherapy after a multidisciplinary consultation. However, as $R$. arrhizus was detected, cultured, and examined with high loads in the arteries, we considered the $\mathrm{T}$ or $\mathrm{NK}$ cells to be secondary to the mucoralean infection, which might play a causal role in the development of the malignancy. We treated him with antifungal therapy rather than chemotherapy, and this led to a successful cure. Patient recovered completely with AMB and lives a normal life up to now. When inoculated to mice, $R$. arrhizus induced $\mathrm{NK} / \mathrm{T}$ cell infiltration with cytotoxic granule associated proteins $(\mathrm{CD} 3+, \mathrm{CD} 8+, \mathrm{CD} 56+$, TIA1+, GZMB+, and PRF+) with hyperplasia (Ki67+) and vascular damage of angioinvasion similar to what was seen in the diseased patient.

LMG lists among the most malignant ulcers and may occur as a granulomatous response of microbial etiology (5-8). Staphyloccus aureus (30), Nocardia farcinica (31), Mycobacterium fortuitum, M. marinum (32), Leishmania infantum (33), and EBV $(9-11,34)$ are among the suspected causative agents. Mucoralean fungi have been reported to cause infections with highly similar clinical features (1, 24-26). Particularly, M. irregularis (28, 29) shows resemblance because this species causes chronic infection in patients without an apparent underlying disease, in contrast to other Mucoralean members which are usually acute in patients with leukemia or ketoacidotic diabetes. The present case of $R$. arrhizus infection exceptionally developed slowly, and the subsequent mouse infection experiments showed pathology characterized by hyperplasia and responsive natural killer cell or/and $\mathrm{T}$ cell infiltration with cytotoxic granule associated proteins, in addition to thin-walled hyphae in tissue and vascular damage.

$R$. arrhizus is the most common etiological agent of ROCM and is strongly associated with facial infection $(20,22,35-37)$. Its prevalence is higher in Asia and South America compared to Europe and North America. Infections mostly involve elderly persons, and males are affected more frequently than females $(38,39)$. Most cases develop in patients with diabetes mellitus, commonly with a history of sinusitis or sometimes tooth extraction (38-40). Clinically, $R$. arrhizus associated ROCM is characterized by a progressive midline facial destruction, often with proptosis, ptosis, ophthalmoplegia, and symptoms of the brain $(22,38-40)$. Initial signs include nasal stuffiness, epistaxis, and facial swelling. With progression, lesions become necrotic with a purulent discharge. Necrosis of the sinuses, nose, face, orbit, and other midline destructions of the face can be seen that are also signs of $\operatorname{LMG}(22,38,39)$.

Angioinvasion is prominent in the pathogenesis of mucormycosis (41). Ibrahim et al. (42) examined the endothelial cell interactions of $R$. arrhizus and found that both alive and killed $R$. arrhizus hyphae were endocytosed by human umbilical vein endothelial cells. The endocytosed hyphae caused a significant endothelial cell damage, suggesting that a factor associated with the fungal cell wall is toxic to these cells. The damage to the endothelial cells resulted in the exposure of vascular smooth muscle cells, which can release large quantities of tissue factors and cause intravascular thrombosis (43). This may be viewed as a characteristic of mucormycosis and ROCM (22). In the present case, we found $R$. arrhizus elements in the artery lumens and walls, where thromboses with angioinvasive, angiocentric, and angiodestructive features suggested fungal damage to the arteries (Figures 2A,B).

R. arrhizus-induced NK/T cell infiltration (CD3+, CD56+, TIA1+, GZMB+, and PRF+) was seen in our patient and the fungus replicated in the mouse infection models. Typically in the LMG patient, $\mathrm{T}$ cell and NK cell infiltration with cytotoxic granule associated proteins (GZMB, PRF, and TIA1) was observed, providing one of the diagnostic criteria $(9-12,44-$ 50). However, roles of these immune cells remain ambiguous with respect to a microbe-induced LMG syndrome $(23,28,48)$. In the present $R$. arrhizus-associated midline face destruction and in previous Mucor-associated midline face destruction, $\mathrm{T}$ cells and/or NK cells with cytotoxic granule associated proteins (GZMB and TIA1) were observed. When introduced to mice, markers were re-expressed (Figures 2F, 3) $(28,29)$. Potenza et al. observed that Mucorales-specific T cells emerged in the course of infection in patients with invasive mucormycoses and that they exhibited direct antifungal activity comparable to that of either polymorphonuclear leukocytes or antigen presenting cells (51). Other experiments have shown that human NK cells or T cells could damage R. arrhizus and other fungi by PRF and GZMBmediated apoptosis and by recruiting other immune cells to bind and then kill fungi $(42,52,53)$. Recently, Deo et al. successfully incubated in vitro panfungal $\mathrm{T}$ cells to increase their number for clinical cell therapy with clinical $R$. arrhizus by the use of the blood and stem cells of healthy donors as the starting material (54). We consider this as an innate immune response, which might be an overreaction, mediated by cytotoxic CD8+ $\mathrm{T}$ and NK cells.

We observed atypical hyperplasia with a high Ki-67 expression in the patient and in mice with high loads of fungal elements. Significantly, these expressions were intensified in the cells around the fungal hypha with irregular nuclear margins and nuclear hyperchromasia positive for Ki-67, CD3, CD56, TIA1, GZMB, and PRF antigens with IHC staining. The phenomenon was also observed in our previous studies $(28,29)$. In 2012, we first reported the inducement of proliferation in a mid-face patient with $M$. irregularis infection (28). When introduced to mice, $M$. irregularis also induced a high Ki-67 expression, which was intensified around its hyphae (29). We considered the high Ki-67 expression around the fungi as activated NK and/or T cells in host defense against pathogens rather than as malignancy (55). Sample size is not sufficient for statistical analysis. However, our findings are suggestive for the role fungus plays in LMG.

In summary, we here describe a mid-face destruction patient, which was diagnosed by the top pathologists in China according to the current criteria of NK/T cell lymphoma, with a negative 
result for EBV and positive for $R$. arrhizus. With a then developed mouse experiment, the "malignant ulcer" in our case was associated with $R$. arrhizus infection, which was responsible for $\mathrm{NK} / \mathrm{T}$ cell infiltration with cytotoxic granule associated proteins (CD3+, CD8+, CD56+, TIA1+, GZMB+, and PRF+), hyperplasia $(\mathrm{Ki} 67+)$, and vascular damage of angioinvasion, suggesting another fungal etiological agent for LMG, which could be eradicated with AMB.

\section{DATA AVAILABILITY STATEMENT}

The original contributions presented in the study are included in the article/supplementary material, further inquiries can be directed to the corresponding author/s.

\section{ETHICS STATEMENT}

The animal study was reviewed and approved by Peking University Third Hospita IRB; approval \#00006761-2015025. Written informed consent has been obtained from the patient for publication of this case report.

\section{AUTHOR CONTRIBUTIONS}

DML and LDL diagnosed and treated the patient and wrote the manuscript. JG and GJZ did the mouse experiment. XLL

\section{REFERENCES}

1. Taali L, Abou-Elfadl M, Fassih M, Mahtar M. Nasal NK/T-cell lymphoma: a tragic case. Eur Ann Otorhinolaryngol Head Neck Dis. (2017) 134:121-2. doi: 10.1016/j.anorl.2016.08.006

2. Thakur JS, Mahajan A, Saluja M, Mohindroo NK. Deceptive nasal NK/T-cell lymphoma. Trop Doctor. (2017) 47:268-71. doi: 10.1177/0049475516684088

3. Woods R. Observations on malignant granuloma of the nose. Br Med J. (1921) 2:65. doi: 10.1136/bmj.2.3159.65

4. McBride P. Photographs of a case of rapid destruction of the nose and face. 1897. J Laryngol Otol. (1991) 105:1120. doi: 10.1017/S0022215100118407

5. Brown CH. Malignant granuloma. Br Med J. (1969) 3:471. doi: 10.1136/bmj.3.5668.471-b

6. Friedmann I, Osborn DA. Malignant granuloma. Br Med J. (1969) 4:431. doi: $10.1136 /$ bmj.4.5680.431-a

7. Harrison DF. Non-healing granulomata of the upper respiratory tract. Br Med J. (1974) 4:205-9. doi: 10.1136/bmj.4.5938.205

8. Friedmann I, Sando I, Balkany T. Idiopathic pleomorphic midfacial granuloma (Stewart's type). J Laryngol Otol. (1978) 92:601-11. doi: 10.1017/S0022215100085819

9. Lim MS, de Leval L, Quintanilla-Martinez L. Commentary on the 2008. WHO classification of mature T- and NK-cell neoplasms. J Hematopathol. (2009) 2:65-73. doi: 10.1007/s12308-009-0034-Z

10. Haverkos BM, Pan Z, Gru AA, Freud AG, Rabinovitch R, Xu-Welliver $\mathrm{M}$, et al. Extranodal NK/T cell lymphoma, nasal type (ENKTL-NT): an update on epidemiology, clinical presentation, and natural history in North American and European cases. Curr Hematol Malig Rep. (2016) 11:514-27. doi: 10.1007/s11899-016-0355-9

11. William BM, Armitage JO. International analysis of the frequency and outcomes of NK/T-cell lymphomas. Best Pract Res Clin Haematol. (2013) 26:23-32. doi: 10.1016/j.beha.2013.04.003

12. Kohrt H, Advani R. Extranodal natural killer/T-cell lymphoma: current concepts in biology and treatment. Leuk Lymphoma. (2009) 50:1773-84. doi: $10.3109 / 10428190903186502$ assisted in the clinical administration. GSH identified the fungus and revised the manuscript. All authors contributed to the manuscript revision, read, and approved the submitted version.

\section{FUNDING}

We gratefully acknowledge the financial support by the Natural Science Foundation of China (31770013, 81571967, and 32070019).

\section{ACKNOWLEDGMENTS}

We especially express our thanks to Xiao Kang Lun for the scientific revision. We gratefully acknowledge Dawei Zhan in the Animal Experimental Department, Fourth Medical Center, PLA General Hospital, for kindly providing the mice and animal laboratory for us. We thank Profs. Zifen Gao and Lin Zhang in Pathology Department for their reference diagnosis of $\mathrm{T}$ cell non-Hodgkin's lymphoma according to the WHO classification of mature T- and NK-cell neoplasms. We thank Xin Yang in the Plastic Surgery Department for the nose transplantation. We also thank Haining Wang, Qin Huang, Wen-Hui Wang, XueYan Lu, Pan-Pan Shang, Ting-Ting Sun, JingWu, and ChunTing Li for their assistance in the clinical administration or laboratory works.
13. Moradi S, Chavoshzadeh Z, Izadyar M, Mahjoub F, Rezaei N. Angiocentric nasal T-cell lymphoma in a patient withidiopathic CD4+ lymphocytopenia. Iran J Allergy Asthma Immunol. (2009) 8:215-8.

14. Tlholoe MM, Kotu M, Khammissa RA, Bida M, Lemmer J, Feller L. Extranodal natural killer/T-cell lymphoma, nasal type: 'midline lethal granuloma.' A case report. Head Face Med. (2013) 9:4. doi: 10.1186/1746-160X-9-4

15. Mendenhall WM, Olivier KR, Lynch JW, Jr., Mendenhall NP. Lethal midline granuloma-nasal natural killer/T-cell lymphoma. Am J Clin Oncol. (2006) 29:202-6. doi: 10.1097/01.coc.0000198738.61238.eb

16. Tomoka T, Powers E, van der Gronde T, Amuquandoh A, Dhungel BM, Kampani C, et al. Extranodal natural killer/T-cell lymphoma in Malawi: a report of three cases. BMC Cancer. (2017) 17:633. doi: 10.1186/s12885-017-3612-y

17. Della-Torre E, Mattoo H, Mahajan VS, Deshpande V, Krause D, Song P, et al. IgG4-related midline destructive lesion. Ann Rheum Dis. (2014) 73:1434-6. doi: 10.1136/annrheumdis-2014-205187

18. Egelund EF, Egelund TA, Ng JS, Wassil SK, Peloquin CA. Posaconazole pharmacokinetics in a 2-year-old boy with rhino-cerebral-orbital zygomycosis. Pharmacotherapy. (2013) 33:e1-8. doi: 10.1002/phar.1172

19. Torre V, Bucolo S, Galletti B, Cavallari V. Midfacial granuloma syndrome or an inflammatory non-specific disease? A case report. J Oral Pathol Med. (2001) 30:190-2. doi: 10.1034/j.1600-0714.2001.300310.x

20. Hilal AA, Taj-Aldeen SJ, Mirghani AH. Rhinoorbital mucormycosis secondary to Rhizopus oryzae: a case report and literature review. Ear Nose Throat J. (2004) 83:556:8-60, 62. doi: 10.1177/014556130408300815

21. Isobe $\mathrm{Y}$, Aritaka N, Sasaki M, Oshimi K, Sugimoto K. Spontaneous regression of natural killer cell lymphoma. J Clin Pathol. (2009) 62:647-50. doi: $10.1136 /$ jcp.2008.062976

22. Li DM, Shang PP, Zhu L, de Hoog GS. Rhino-orbital-cerebral mycosis and cavernous thromboses. Eur J Inflamm. (2014) 12:1-10. doi: $10.1177 / 1721727 X 1401200101$

23. Zhang XF YQ, Yang XC, Deng J, Hao F, Song Q. One case of nasal tye NK/T - cell lymphoma. J Clin Dermatol. (2015) 34:752-3. doi: 10.1016/j.amjoto.2014.07.012 
24. Aydogdu I, Sari R, Mizrak B. Case report. Rhinocerebral zygomycosis. Mycoses. (2001) 44:59-60. doi: 10.1046/j.1439-0507.2001.00615.x

25. Kameh DS, Gonzalez OR, Pearl GS, Walsh AF, Gambon T, Kropp TM. Fatal rhino-orbital-cerebral zygomycosis. South Med J. (1997) 90:1133-5. doi: 10.1097/00007611-199711000-00015

26. Luemsamran $\mathrm{P}$, Pornpanich K, Uiprasertkul M, Sakolsatayadorn $\mathrm{N}$, Vangveeravong S. NK/T-cell lymphoma of the nasal cavity causing contralateral dacryoadenitis. Orbit. (2013) 32:250-2. doi: $10.3109 / 01676830.2013 .788665$

27. Zhang Y, Wang T, Liu GL, Li J, Gao SQ, Wan L. Mucormycosis or extranodal natural killer/T cell lymphoma, similar symptoms but different diagnosis. $J$ Mycol Med. (2016) 26:277-82. doi: 10.1016/j.mycmed.2016.04.005

28. Li DM, Lun LD. Mucor irregularis infection and lethal midline granuloma: a case report and review of published literature. Mycopathologia. (2012) 174:429-39. doi: 10.1007/s11046-012-9559-2

29. Ge J, Zhou YB, Li DM. Studies of atypical hyperplasia in mice caused by Mucor irregularis and Rhizopus oryzae isolated from lethal midline granuloma. Mycosystema. (2019) 38:1314-22. doi: 10.13346/j.mycosystema.190166

30. Borg AJ, Kumagai-Braesch M, Moller E. 15-Deoxyspergualin inhibits interleukin 6 production in in vitro stimulated human lymphocytes. Transpl Immunol. (1996) 4:133-43. doi: 10.1016/S0966-3274(96)80007-4

31. Eisenblatter M, Buchal A, Gayum H, Jasny E, Renner Viveros P, Ulrichs T, et al. Nocardia farcinica activates human dendritic cells and induces secretion of interleukin-23 (IL-23) rather than IL-12p70. Infect Immun. (2012) 80:4195202. doi: 10.1128/IAI.00741-12

32. Mehrotra J, Bisht D, Tiwari VD, Sinha S. Serological distinction of integral plasma membrane proteins as a class of mycobacterial antigens and their relevance for human T cell activation. Clin Exp Immunol. (1995) 102:626-34. doi: 10.1111/j.1365-2249.1995.tb03863.x

33. Junior AM, de Amorim Carvalho FA, de Oliveira Dantas W, Gomes LC, da Silva AB, de Sousa Cavalcante MM, et al. Does Leishmaniasis disease alter the parenchyma and protein expression in salivary glands? Exp Biol Med. (2016) 241:359-66. doi: 10.1177/1535370215614658

34. Harabuchi Y, Yamanaka N, Kataura A, Imai S, Kinoshita T, Mizuno F, et al. Epstein-Barr virus in nasal T-cell lymphomas in patients with lethal midline granuloma. Lancet. (1990) 335:128-30. doi: 10.1016/0140-6736(90)90002-M

35. Gryganskyi AP, Golan J, Dolatabadi S, Mondo S, Robb S, Idnurm A, et al. Phylogenetic and phylogenomic definition of rhizopus species. G3. (2018) 8:2007-18. doi: 10.1534/g3.118.200235

36. Mulki R, Masab M, Eiger G, Perloff S. Lethargy and vision loss: successful management of rhinocerebral mucormycosis. BMJ Case Rep. (2016) 2016:bcr2016215855. doi: 10.1136/bcr-2016-215855

37. Li DM, de Hoog GS. Cerebral phaeohyphomycosis-a cure at what lengths? Lancet Infect Dis. (2009) 9:376-83. doi: 10.1016/S1473-3099(09)70131-8

38. Erami M, Shams-Ghahfarokhi M, Jahanshiri Z, Sharif A, RazzaghiAbyaneh M. Rhinocerebral mucormycosis due to Rhizopus oryzae in a diabetic patient: a case report. J Mycol Med. (2013) 23:123-9. doi: 10.1016/j.mycmed.2013.04.002

39. Ervens J, Ghannoum M, Graf B, Schwartz S. Successful isavuconazole salvage therapy in a patient with invasive mucormycosis. Infection. (2014) 42:429-32. doi: 10.1007/s15010-013-0552-6

40. Kazak E, Aslan E, Akalin H, Saraydaroglu O, Hakyemez B, Erisen $\mathrm{L}$, et al. A mucormycosis case treated with a combination of caspofungin and amphotericin B. J Mycol Med. (2013) 23:179-84. doi: 10.1016/j.mycmed.2013.06.003

41. Filler SG, Sheppard DC. Fungal invasion of normally non-phagocytic host cells. PLoS Pathog. (2006) 2:e129. doi: 10.1371/journal.ppat.0020129

42. Ibrahim AS, Spellberg B, Avanessian V, Fu Y, Edwards JE Jr. Rhizopus oryzae adheres to, is phagocytosed by, and damages endothelial cells in vitro. Infect Immun. (2005) 73:778-83. doi: 10.1128/IAI.73.2.778-78 3.2005

43. Stampfuss JJ, Censarek P, Fischer JW, Schror K, Weber AA. Rapid release of active tissue factor from human arterial smooth muscle cells under flow conditions. Arterioscler Thromb Vasc Biol. (2006) 26:e34-7. doi: 10.1161/01.ATV.0000216407.89528.b0

44. Yanagi H, Nakamura Y, Takagi D, Kubota K. Extranodal natural killer/Tcell lymphoma: a diagnostic dilemma. Rhinology. (2012) 50:325-31. doi: 10.4193/Rhin11.245

45. Haverkos BM, Coleman C, Gru AA, Pan Z, Brammer J, Rochford R, et al. Emerging insights on the pathogenesis and treatment of extranodal NK/T cell lymphomas (ENKTL). Discov Med. (2017) 23:189-99.

46. Tsokos M, Fauci AS, Costa J. Idiopathic midline destructive disease (IMDD): a subgroup of patients with the "midline granuloma" syndrome. Am J Clin Pathol. (1982) 77:162-8. doi: 10.1093/ajcp/77.2.162

47. Ishii Y, Yamanaka N, Ogawa K, Yoshida Y, Takami T, Matsuura A, et al. Nasal T-cell lymphoma as a type of so-called "lethal midline granuloma". Cancer. (1982) 50:2336-44. doi: 10.1002/1097-0142(19821201)50:11<2336::AIDCNCR2820501120>3.0.CO;2-C

48. Rodrigo JP, Suarez C, Rinaldo A, Devaney KO, Carbone A, Barnes L, et al. Idiopathic midline destructive disease: fact or fiction. Oral Oncol. (2005) 41:340-8. doi: 10.1016/j.oraloncology.2004.10.007

49. Metgud RS, Doshi JJ, Gaurkhede S, Dongre R, Karle R. Extranodal NK/T-cell lymphoma, nasal type (angiocentric T-cell lymphoma): a review about the terminology. J Oral Maxillofac Pathol. (2011) 15:96-100. doi: 10.4103/0973-029X.80016

50. Vose J, Armitage J, Weisenburger D, International TCLP. International peripheral T-cell and natural killer/T-cell lymphoma study: pathology findings and clinical outcomes. J Clin Oncol. (2008) 26:4124-30. doi: 10.1200/JCO.2008.16.4558

51. Potenza L, Vallerini D, Barozzi P, Riva G, Forghieri F, Zanetti E, et al. Mucorales-specific T cells emerge in the course of invasive mucormycosis and may be used as a surrogate diagnostic marker in high-risk patients. Blood. (2011) 118:5416-9. doi: 10.1182/blood-2011-07-366526

52. Schmidt S, Tramsen L, Perkhofer S, Lass-Florl C, Hanisch M, Roger F, et al. Rhizopus oryzae hyphae are damaged by human natural killer (NK) cells, but suppress NK cell mediated immunity. Immunobiology. (2013) 218:939-44. doi: 10.1016/j.imbio.2012.10.013

53. Schmidt S, Tramsen L, Lehrnbecher T. Natural killer cells in antifungal immunity. Front Immunol. (2017) 8:1623. doi: 10.3389/fimmu.2017.01623

54. Deo SS, Virassamy B, Halliday C, Clancy L, Chen S, Meyer W, et al. Stimulation with lysates of Aspergillus terreus, Candida krusei and Rhizopus oryzae maximizes cross-reactivity of anti-fungal T cells. Cytotherapy. (2016) 18:65-79. doi: 10.1016/j.jcyt.2015.09.013

55. Ruibal P, Oestereich L, Ludtke A, Becker-Ziaja B, Wozniak DM, Kerber R, et al. Unique human immune signature of Ebola virus disease in Guinea. Nature. (2016) 533:100-4. doi: 10.1038/nature17949

Conflict of Interest: The authors declare that the research was conducted in the absence of any commercial or financial relationships that could be construed as a potential conflict of interest.

Copyright (c) 2021 Li, Lun, Ge, Zhang, Li and de Hoog. This is an open-access article distributed under the terms of the Creative Commons Attribution License (CC $B Y)$. The use, distribution or reproduction in other forums is permitted, provided the original author(s) and the copyright owner(s) are credited and that the original publication in this journal is cited, in accordance with accepted academic practice. No use, distribution or reproduction is permitted which does not comply with these terms. 